\title{
Article
}

\section{Why the idea of framework propositions cannot contribute to an understanding of delusions}

\author{
Thornton, Tim
}

Available at http://clok.uclan.ac.uk/3226/

Thornton, Tim ORCID: 0000-0002-0137-1554 (2008) Why the idea of framework propositions cannot contribute to an understanding of delusions. Phenomenology and the Cognitive Sciences, 7 (2). pp. 159-175. ISSN 15687759

It is advisable to refer to the publisher's version if you intend to cite from the work. http://dx.doi.org/10.1007/s11097-007-9079-6

For more information about UCLan's research in this area go to http://www.uclan.ac.uk/researchgroups/ and search for <name of research Group>.

For information about Research generally at UCLan please go to http://www.uclan.ac.uk/research/

All outputs in CLoK are protected by Intellectual Property Rights law, including Copyright law. Copyright, IPR and Moral Rights for the works on this site are retained by the individual authors and/or other copyright owners. Terms and conditions for use of this material are defined in the policies page.

\section{CLoK}

Central Lancashire online Knowledge www.clok.uclan.ac.uk

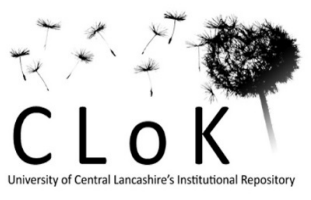




\title{
Why the idea of framework propositions cannot contribute to an understanding of delusions
}

\begin{abstract}
One of the tasks that recent philosophy of psychiatry has taken upon itself is to extend the range of understanding to some of those aspects of psychopathology that Jaspers' deemed beyond its limits. Given the fundamental difficulties of offering a literal interpretation of the contents of primary delusions, a number of alternative strategies have been put forward including regarding them as abnormal versions of framework propositions described by Wittgenstein in On Certainty. But although framework propositions share some of the apparent epistemic features of primary delusions, their role in partially constituting the sense of inquiry rules out their role in helping to understand delusions.
\end{abstract}

\section{1: The problem of understanding delusions}

In this section, I outline Jaspers' view of understanding and, in that context, some of the difficulties of making sense of primary delusions.

According to Jaspers, there are two kinds of intelligibility relevant to psychiatry. There is, on the one hand, natural scientific explanation and, on the other, a contrasting kind of meaningful understanding. Jaspers divides the latter into two forms: static understanding, also called 'phenomenology', and genetic understanding. Both of these are also called forms of empathy, although he seems to favour using 'empathy' for genetic understanding. He says, for example,

We sink ourselves into the psychic situation and understand genetically by empathy how one psychic event emerges from another. [Jaspers 1997: 301]

Whilst the idea of sinking into a situation is something like a metaphor (in fact more like an instance of Wittgensteinian secondary sense), Jaspers does attempt some characterisation of empathy. It is needed and appropriate for grasping subjective as opposed to objective symptoms. Objective symptoms are those that can be detected by anyone capable either of sense perception or of logical thought. In other words, the detection or comprehension of objective symptoms does not require the possession of any specific kind of mind. In Nagel's phrase, they fit into a view from nowhere [Nagel 1986]. By contrast, the detection or comprehension of subjective symptoms requires having and sharing a particular kind of mind.

Subjective symptoms cannot be perceived by the sense-organs, but have to be grasped by transferring oneself, so to say, into the other individual's psyche; that is, by empathy. [Jaspers 1968: 1313]

Whilst understanding as a whole involves a kind of shared participation in a form of life, it divides into two kinds. Static understanding or phenomenology concerns the nature or quiddity of kinds of mental state, achieved through a quasi-perceptual investigation. It is an attempt to get clear on what kinds of mental state are like. Genetic understanding concerns the evolution of, or connection between, mental states:

When the contents of thoughts emerge one from another in accordance with the rules of logic, we understand the connexions rationally. But if we understand the content of the thoughts as they have arisen out of the moods, wishes, and fears of the person who thought them, we understand the connexions psychologically or empathetically. [Jaspers 1974: 83]

Unlike most contemporary accounts, Jaspers suggests that the 'rational contents' of thoughts and, in psychopathology, of delusions do not belong to empathy. Thus, for example, the rational connections between thoughts are not a proper part of genetic understanding. Empathy is thus more narrowly circumscribed than what belongs in a simulation theorist's account of other minds, 
for example [Heal 1995]. I will suggest that this may reflect and overly narrow restriction, by Jaspers, of rationality to that which can be codified in, for example, first order logic. Elsewhere Jaspers describes these connections as 'ideally typical' rather than, for example, inductive. The picture is thus one in which to understand empathically another's mental states depends on having and sharing the same kind of mind and thus finding particular kinds of thought-transitions natural.

Although Jaspers suggests that empathy lies at the heart of psychopathology, he also claims that some central psychopathological symptoms cannot be understood this way. He suggests that delusions can be divided into two kinds according to their origins. Secondary delusions emerge understandably from preceding affects such as shattering, mortifying, guilt-provoking or other such experiences. Primary delusions by contrast are psychologically irreducible.

Thus although Jaspers places empathic understanding (both static and genetic) at the heart of psychopathology and thus psychiatry, he also argues that some of the key phenomena that characterise psychopathology cannot be understood (they may be explained in natural scientific terms). They are un-understandable. If Jaspers is correct then psychiatry has a fundamental limitation: it cannot achieve empathic understanding of a central tract of psychopathological experience.

But this also raises a further intellectual tension of which Jaspers is less aware. His account of empathy shares an assumption with much contemporary philosophy of mind. Being empathically understandable is a condition for having a mind. Empathy and mentality go hand in hand. But if so, primary delusions are a potential counter instance in, apparently, being mental whilst simultaneously resisting empathy. The main subject of this paper is one such attempt to ease this tension.

First, however, why should delusions not be understandable? Jaspers takes passivity phenomena, such as thought insertion or made actions, as paradigms of such un-understandability. Such delusions seem, on the face of it, to concern impossible states of affairs. A subject thinks a thought, for example, which is somehow not her own but not in the everyday sense of acquiring another person's thoughts through influence or testimony. How is it possible, however, to think a thought which is not, ipso facto, one's own? What sense can we make of that possibility and thus what sense can we make of this kind of delusion?

In fact, however, there are problems understanding less outré delusions. Take the example of a delusion anecdotally reported to be popular in the 1980s in which a subject apparently believes that there is a nuclear power station inside him but which is combined with ordinary beliefs about the relative sizes of power stations and humans. Can we properly say that he believes that he has a nuclear power station inside him? The problem is this. Such a belief content carries implications about relative sizes which are not accepted by the subject. The putative atomic content clashes - rationally and conceptually - with other beliefs he or she holds. (The qualification 'rationally and conceptually' might suggest that this is not a failure of empathy but rational understanding in Jaspers' terms. But that is, perhaps, because Jaspers has an overly restricted notion of a rational connection comprehension of which requires no particular kind of mind. In fact, however, codifying the conceptual connections which underpin shared understanding would not in general be possible. Sharing an understanding of such connections is part of a shared mentality.) Thus although the subject uses the words 'I have a nuclear power station inside me', there is a problem in saying, from the third person stance, that he believes that he has a nuclear power station inside him. He does not believe what we would have to believe in addition to believe that.

A further feature of at least some delusions is a weakness of motivational force. For example, a subject whose laboratory work was interrupted by the apparent presence of fire breathing animals reported at a seminar of philosophers that she made no attempt to alert security or the fire brigade 
but could not subsequently explain why she did not act in that obvious way. Louis Sass describes this sort of case thus.

[M]any schizophrenics who seem to be profoundly preoccupied with their delusions, and who cannot be swayed from belief in them, nevertheless treat these same beliefs with what seems a certain distance or irony... A related feature of schizophrenic patients is what has been called their 'double bookkeeping'... A patient who claims that the doctors and nurses are trying to torture and poison her may nevertheless happily consume the food they give her; a patient who asserts that the people around him are phantoms or automatons still interacts with them as if they were real. [Sass 1994: 21]

The problem is that the absence of the actions that they would otherwise rationalise undermines the ascription of beliefs. Does Sass' patient really believe that the doctors and nurses are trying to torture and poison her?

The underlying problem that cases of these sorts present for an empathic understanding is that the breakdown of connections between beliefs or between beliefs and actions undermine grounds for the ascription of a specific content to the subject. (An alternative description of schizophrenic delusion is that it involves a global existential orientation rather than a local breakdown. I will return to this later.) Whilst for convenience we might say of someone that they think they are having someone else's thoughts, it is far from clear that this really is a conceivable thought, a thought we can ascribe to others or empathically participate in. It appears instead to be brutely alien. At the same time, however, mindedness and empathy seem to go hand in hand. What options are there for making sense of cases like these?

One response is simultaneously to give up both empathy and intentional mental content at the same time. At the end of an article pessimistically summarising the history of the analysis of delusions as 'wrong beliefs' German E. Berrios, a psychiatrist with an academic interest in the history of psychiatry makes the following comment.

Delusions are likely to be empty speech acts, whose informational content refers to neither world nor self. They are not the symbolic expression of anything. Its 'content' is but a random fragment of information 'trapped' in the very moment the delusion becomes crystallized. [Berrios 1991: 12]

Berrios suggests that the expression of a delusion is, strictly, empty of content, 'not the symbolic expression of anything'. This would place delusion outside the subject matter of understanding. The problem with such an approach is that it does not seem to fit the clinical facts. Whilst, there are problems in taking delusions to be ordinary beliefs, it appears that in at least some cases, they have some rational connections to some actions, beliefs and utterances.

By contrast with Berrios' renunciation of both empathy and mentality, Brendan Maher's influential model of delusion attempts to augment empathic understanding. In 'Anomalous Experience in Everyday Life: Its significance for psychopathology,' he suggests, first, that there is continuity between experiences which prompt delusions and an everyday experience that something significant has happened [Maher 1999]. Delusions can then be understood as a rational response to the experience: a hypothesis, for example, to explain that feeling. The combined strategy aims to bring delusions within an expanded notion of understanding.

The model has, however, two fundamental and interrelated weaknesses. On the one hand, consider the well known case that Maher cites of the subject who, on looking at marble tables in a café, becomes convinced that the world is about to end. Maher suggests, following Jaspers himself, that, in fact, a feeling of significance preceded the observation of the tables and only subsequently became attached to the observation and then, presumably, was elaborated upon. Maher suggests that if the subject can find nothing in the immediate environment to explain the 
feeling then 'everything must have changed in some fundamental way' [ibid: 560]. But now the problem is that whilst Maher may have shed light on the initial experience - which may be continuous with everyday cases - the adoption and maintenance of the delusion in the face of critical scrutiny becomes ununderstandable.

On the other hand, consider thought insertion: the delusion that one has, or that one's mind is a projection screen for, other people's thoughts. Chris Frith proposes an explanation of it, in line with Maher's model, based on the breakdown of a sub-personal mechanism. Just as the brain 'signals' a distinction between changes of the visual field produced by moving one's eyes and those that result from changes in the world by labeling the former, so thoughts are also normally labeled as the product of one's own thinking. Frith suggests that, if such a labeling mechanism were to break down, one would experience one's thoughts as somehow not one's own, as alien. It is then a simple matter to ascribe them to another. 'If we found ourselves thinking without any awareness of the sense of effort that reflects central monitoring, we might well experience these thoughts as alien and, thus, being inserted' [Frith 1992: 81].

The problem in this case is not the transition from bizarre experience to rationalizing thought. It is the experience in the first place. Just what would it be to experience a thought as somehow not one's own? In this case, the problem is made worse, not better, by the everyday experience of having thoughts pop into one's mind. What could a more fundamentally alien case of a thought arising be like?

The overall problem takes the form of a dilemma for Maher's account. If the basic model is that of an understandable response to an abnormal experience then given the bizarre quality of the delusions in question ('best quality delusions' in Bill Fulford's phrase [Fulford 1989: 202]) two adjustments can be made to try to capture that quality.

- Either the experience is bizarre and the response to it is understandable (as in the case of thought insertion). In which case, how can we understand the experience? This is, in effect, a problem of static understanding.

- Or the experience is at least continuous with normal experiences but the response to it is not (as in the case of the café tables and the end of the world). In which case, how can we understand the transition? This is, in effect, a problem of genetic understanding.

Thus it seems that neither Berrios' aim to place delusions firmly outside the range of understanding because they are not meaningful at all nor Maher's attempt to extend the range of understanding succeed.

I will now turn to a different proposal. Delusions are abnormal framework propositions.

\section{2: The proposal: delusions are abnormal framework propositions}

In a paper concerned with the interpretation of the Capgras delusion, John Campbell suggests an analogy between delusions and Wittgenstein's On Certainty account of 'framework' or 'hinge' propositions. He takes as is starting point the fact that Wittgenstein discusses the epistemological status of a heterogeneous class of propositions such as 'There are lots of objects in the world', 'The world has existed for quite a long time', 'There are some chairs and tables in this room', 'This is one hand and this is another'. Reporting that Wittgenstein claims that propositions such as these form the framework within which all testing of hypotheses or justification of knowledge claims takes place, Campbell puts forward the following proposal:

In these terms, an obvious question to raise about delusions is whether the delusional beliefs do not have, for the subject, the epistemological status of Wittgenstein's framework propositions. [Campbell 2001: 96]

Reporting the proposal with approval Naomi Eilan says: 
Our framework beliefs are those fundamental beliefs we do not question, and which globally constrain our inferences and our interpretation of our experiences... The suggestion is that primary paranoid beliefs, such as that the IRA is out to get one, should be treated as constraining one's reasoning and interpretation of one's experience in an analogous manner. They are resistant to counter-evidence because of their fundamental framing role... (But contra the noise option, this does not render their expression senseless.)... [Eilan 2000: 108-9]

Two features of framework propositions make the analogy with delusions promising.

Firstly, framework propositions provide the context for the practice of giving and asking for reasons which corresponds to making claims of knowledge or doubt. They themselves comprise a background of certainties that are held immune from doubt. They are not themselves objects for possible knowledge but instead make knowledge claims possible. By construing delusions as framework propositions one can begin to explain their incorrigibility and the role they might play in structuring other claims. '[T]hey are treated as the background assumptions needed for there to be any testing of the correctness of propositions at all.' [Campbell 2001: 96]

Secondly, unlike more traditional epistemological accounts, Wittgenstein's picture suggests that these certainties are heterogeneous and have everyday worldly subject matters. They are not restricted, for example, to claims about sense data or other more familiar philosophical foundations. They can have wider or narrower significance. Thus the specificity of delusions is no objection to them playing just this role.

Of course to play a role in accounting for delusions the framework propositions will have, in some sense, to be abnormal. One possibility is that such abnormality might simply be nonstandard or false by our lights. But that idea needs handling with some care. Take the case of subjects with organically based pathologies who confabulate about their present life, mixing up real and false memories. In normal circumstances, some memories, at least, might play the role of framework propositions. Wittgenstein gives the example of knowledge of his own name and knowledge that he has not visited the moon as examples. Having false memories is part of everyday life and need not amount to a delusion. But perhaps when a memory is playing a framework role, falsity is sufficient to amount to delusion. Having false memories of one's name or past visits to the moon, for example, are not mere slips.

Does the analogy with framework propositions help shed light on delusions? At first sight it seems that it does. The structural parallel suggests a way of coming to grips with the role of a delusion in a subject's thinking. It thus serves to shed light on how the subject could entertain a delusion in the context of evidence that would normally count against it: it is being held immune from such evidence. (Elsewhere Wittgenstein comments: “But, if you are certain, isn't it that you are shutting your eyes in the face of doubt?” - They are shut.' [Wittgenstein 1953 §224].)

But, of course, coming to grips with delusions is not straight-forward even using the analogy of framework propositions. Eilan suggests the following brief account of a partial, shifting understanding:

[The proposal] captures beautifully at least part of what we try to do when we do understand expressions of delusions, and the inherent limitations on such understanding. We can, as we say, fall in, to an extent, with a deluded subject's reasoning. In doing this we attempt, precisely, to let a primary belief function as a framework belief. But this is something we cannot actually sustain precisely because we cannot treat it as more than a restricted hypothesis. We cannot put it on a level with all our real framework beliefs, and adjust the latter and our specific beliefs and reasoning accordingly. Hence the sense of wild unpredictability for us of the way in which, for the schizophrenic, other claims get absorbed in the new framework. [Eilan 2000: 109] 
The suggestion appears to be this. We can begin to understand expressions of delusions by taking them to express abnormal framework beliefs, beliefs that have framework propositions as their contents. We can thus predict that these will be held firm and not subject to empirical testing which accords with the incorrigibility of delusions. But we can only begin to understand them and subsequent predictions in general will not be reliable because we cannot fit these abnormal framework beliefs into the background of certainties shared with the rest of the community. Thus the proposal appears to help to 'make the borderline nature of these states, the way in which they threaten genetic understanding, integral to the nature of this peculiar understanding' [ibid: 108]. I will argue, however, that this is not so.

\section{3: Problems with the proposal}

It is important to be clear what the proposal is. The idea of framework propositions is supposed to extend the range of understanding to embrace delusions as a whole. The proposal is not so ambitious as to offer to translate or interpret individual expressions of delusions. It is not in that sense a practical tool. But it is supposed to enable understanding to embrace the idea of delusions as both content laden but also as peculiar and strange as they are found to be. It is supposed to 'solve simultaneously for understanding and utter strangeness' in Eilan's useful metaphor [Eilan 2000: 97]. Delusions as a whole are brought within the realm of understanding even if the content of each and every delusion remains baffling.

I think, however, that it cannot do this. Even at this level of generality, we cannot really understand the proposal. There are three inter-related reasons for this which I will first state and summarise here and then explicate further in the rest of this section.

1. Framework propositions are identified from 'within' a world-view.

2. There is a close relation between the epistemic role of framework propositions emphasised by Campbell and Eilan and a sense-giving role.

3. There are no 'external' criteria for framework propositions.

Framework propositions are not identified as a general type in the way that other proposed philosophical foundations might be. They are instead identified piecemeal from within a mature worldview. But this presupposes, rather than helping to explain, their intelligibility and thus undermines their ascription in the case of delusions.

This reliance on shared intelligibility is an essential aspect of framework propositions because their epistemological foundational role - the extent to which they help characterise what has to be taken for granted for empirical judgements to be possible - goes hand in hand with a sense-giving role. Because they are supposed to shed light on delusions, we need to be able to grasp the idea of something like false framework propositions. But when a framework proposition is playing a role in constituting sense, its negation makes no sense in that context. Against the background of our own framework propositions, a false framework proposition is like a nonsensical sense. That idea is incoherent, not one we can in general understand.

The mechanical labels 'framework' and 'hinge propositions' may suggest a description of thought could be given independently of content. If one could identity the bearers of content - by contrast with the content itself - within the mind in syntactic terms, it might seem possible to identify some thoughts which were held fast whilst other thoughts turned about them. But this idea both presupposes the possibility of the reduction of meaning to structural entities in the head and falls foul of Wittgenstein's suggestion that framework propositions are not even mental attitudes at all, which runs counter to Eilan's assumption that they are beliefs.

I will now take these points a little more slowly.

Framework propositions are identified from 'within' a world-view. 
One of the features of framework propositions already noted is that they form a heterogeneous collection or motley. They are of very different kinds, both personal and interpersonal, theoretically complex or basic, general and particular.

Traditional philosophical foundations, by contrast, form unified general kinds. According to epistemology influenced by Descartes’ Argument from Illusion, for example, empirical judgement is supposed to stand on the totality of neutrally describable experiences. Such kinds of epistemological foundation can be identified as a whole, independently of the particular beliefs or judgements which are supposed to be based on them. (This observation forms an important part of Michael Williams' diagnosis of the sources scepticism [Williams 1996]. Denying that there are such kinds as the totality of empirical beliefs and the totality of neutrally describable experience on which the former is based helps to show that scepticism, which takes such a distinction for granted, is problematic and unnatural.)

But because framework propositions do not form such a kind, there is no shortcut to identify them. Nor, despite their fundamental nature, are they foundational in the following sense. They are not learned before more problematic beliefs which might be justified in terms of them. So they cannot be identified as what is first held to be the case. They have instead to be identified piecemeal from 'within' a mature worldview.

I do not explicitly learn the propositions that stand fast for me. I can discover them subsequently like the axis around which a body rotates. This axis is not fixed in the sense that anything holds it fast, but the movement around it determines its immobility. [Wittgenstein 1969 §152]

(What of the fact that delusions can be grouped into kinds or forms? Might shared forms of delusion undermine the objection here? This would only help the proposal for understanding delusions if the forms could be identified prior to their meanings or contents. If, as seems more likely, kinds or forms are abstractions from contents, it will not help.)

In the first person case, framework propositions are identified through an articulation of what serves as a reason for what and what is not held up to question. But that presupposes, rather than help to shed light on, the kind of understanding that is in question: roughly, genetic understanding or empathy.

In third person cases, such propositions are shown. There is a hint of this in this passage of On Certainty:

Am I not getting closer and closer to saying that in the end logic cannot be described? You must look at the practice of language, then you will see it. [Wittgenstein 1969 §500501]

But again, the ability to articulate others' framework propositions presupposes shared understanding. Wittgenstein emphasises the claim that the ascription of certainty and knowledge are part of a broader structure of shared understanding.

Thus the framework propositions described by Wittgenstein are identified by exploring rational connections within a worldview both in one's own case - as an exercise, perhaps, in greater selfconscious understanding - and in the case of others. There is, in other words, a dependence between being able to ascribe, to a proposition, a fundamental epistemic status and first being able to understand it and its relation to other things which are either held to be certain or which are subject to claims of knowledge or doubt. This puts under some tension the idea that one can use the idea of framework propositions to understand something which cannot be so accommodated. 


\section{There is a close relation between the epistemic and sense-giving roles of framework propositions.}

Further light is shed on how framework propositions are identified by considering their joint role both epistemologically, as emphasised by Campbell and Eilan, but also in marking the limits of possible inquiry, of what it would make sense to doubt or justify. Framework propositions play a role in constituting the limits of sense. In this, they are akin to grammatical rules that simultaneously determine the correct use of expressions and hence what can be said to be possible and impossible.

Grammatical rules are central to the later Wittgenstein's normative conception of language. By determining how words should be used, they constitute the limits of sense. Correct statements of grammatical rules are not true in the sense of describing how things are but rather collectively stipulate the meaning of words. Given Wittgenstein's practical turn in the philosophy of language - 'To understand a language means to be master of a technique' [Wittgenstein 1953 §199 - these are closely tied to grasp of a technique. Grammatical rules encode the rules of the practice of linguistic representation.

Wittgenstein argues that this is also the correct way to understand mathematical and logical propositions, as a varieties of grammatical rule. They are norms for the correct use of terms in empirical judgements and thus, again, tied to techniques of linguistic representation. They neither describe abstract entities nor extra-empirical constraints on the mind. 'Their a priori status is due to the fact that, in spite of their descriptive appearance, their role is a normative one: nothing which contravenes them counts as an intelligible description of reality.' [Glock 1996: 233-4]

In Zettel, the connection between grammatical rules, sense and possibility is exemplified in a discussion of another subset of grammatical rules: those governing colour.

"But if by 'bluish yellow' I mean green, I am taking this expression in a different way from the original one. The original conception signifies a different road, a no thoroughfare."

But what is the right simile here? That of a road that is physically impassable, or of the non-existence of a road? i.e. is it one of physical or of mathematical impossibility?

We have a colour system as we have a number system.

Do the systems reside in our nature or in the nature of things? How are we to put it?--Not in the nature of numbers or colours.

Like grammatical rules / logic, they partially constitute the rules of inquiry. [Wittgenstein 1967 §356-7]

Given the colour system, only some combinations of colour names have sense - 'reddish yellow' but not 'reddish green', for example - and thus only some empirical judgements can be framed. Articulating the rules governing correct combinations also articulates what is possible and thus plays a fundamental role in colour judgement even if learning the rules and hence the techniques of colour judgement go hand in hand.

Wittgenstein's description from Zettel is a half way house between more formal grammatical rules such as logic or mathematics and the motley of framework propositions in On Certainty. Whilst there are important similarities there are some differences between grammatical rules and framework propositions which I will declare first. Firstly, there is no prospect of surveying the latter framework and summarising it in something like a series of mathematical proofs or the colour octohedron depiction of colour grammar of which Wittgenstein approves [Wittgenstein 1975: 75]. More significantly, statements of grammatical rules are not true descriptions of anything and their negation makes no sense. By contrast, statements of framework propositions seem to be true, even if never usually asserted, and their negations can make sense. This point 
needs handling with some care and I will return to it.

Nevertheless, despite these differences, framework propositions play a similar role in constituting a background against which empirical judgements can be made and which is required for us to make sense of empirical inquiry. Like grammatical rules, including those of mathematics and colour relations, a practical grasp of them forms the background of representational techniques against which empirical judgements can be made. Marie McGinn summarises this aspect of framework propositions in the following way: 'The judgements of the frame are not applying our language in propositions whose meaning is independent of their truth-value; for these judgements, their being true in part determines the meaning of the expressions being employed' [McGinn 1989: 142]

This sense-constituting role is highlighted in a large number of passages in On Certainty of which the following are just a sample:

Only in certain cases is it possible to make an investigation "is that really a hand?" (or "my hand"). For "I doubt whether that is really my (or a) hand" makes no sense without some more precise determination. One cannot tell from these words alone whether any doubt at all is meant - nor what kind of doubt. [Wittgenstein 1969 §372.

For suppose you were guiding a blind man's hand, and as you were guiding it along yours you said "this is my hand"; if he then said "are you sure?" or "do you know it is?", it would take very special circumstances for that to make sense. [Wittgenstein 1969 §413]

But on the other hand: how do I know that it is my hand? Do I even here know exactly what it means to say it is my hand? [Wittgenstein 1969 §414]

If, therefore, I doubt or am uncertain about this being my hand (in whatever sense), why not in that case about the meaning of these words as well? [Wittgenstein 1969 §456]

The context of shared framework propositions constitutes the limits of what makes sense. To learn how to make judgements requires grasping this framework much as understanding how to make colour judgements requires understanding that framework. Thus framework propositions describe the techniques of empirical judgement. They are, in McGinn's useful description, preepistemic.

Thus, my certainty regarding, say, the judgement 'This is a hand' is to be seen as a preepistemic attitude that is in part constitutive of my practical ability to speak the language. The judgement that this is a hand is not a piece of knowledge - a true, justified belief, based on evidence - but an authoritative expression of my established mastery of English. [McGinn 1989: 144]

As mentioned above, unlike more formal grammatical rules, the same descriptions that can express framework propositions can also express empirical claims. This leads to a blurring of the boundary between fixing the rules of empirical inquiry and making a judgement within that context.

Imagine that the schoolboy really did ask "and is there a table there even when I turn round, and even when no one is there to see it?” Is the teacher to reassure him--and say "of course there is!"?...

'The question doesn't arise at all.' Its answer would characterise a method. But there is no sharp boundary between methodological propositions and propositions within a method.

But wouldn't one have to say then, that there is no sharp boundary between propositions of logic and empirical propositions? The lack of sharpness is that of the boundary between rule and empirical proposition. [Wittgenstein 1969 §314-9] 
The lack of sharpness here concerns the fact that the same form of words can be used as either an empirical claim or as a rule governing empirical claims. But this does not undermine the idea that framework propositions, when used to articulate the background certainties, partially constitute the rules governing empirical inquiry and hence the techniques of description.

Given that the proposal in question is to shed light on delusions, for it to work the propositions in question will have to be suitably abnormal. Thus we need, at the very least, to be able to understand the idea of something like framework proposition that we would take for granted to be false. In fact, this is at two removes from what is actually needed. Delusions are not just false but can be strange or impossible. Further, given the idea that framework propositions encode preepistemic practical attitudes, understanding a false framework belief, as Eilan describes them, is still some way off. But even that idea seems impossible.

As I reported above, although framework propositions play a role akin to statements of grammatical rules, negating the statement of a framework proposition need not produce nonsense. Under suitable circumstances even the claim 'this is a hand', based on a perceptual demonstrative, can be used to make an empirical judgement. In those rare circumstances we can make sense of its negation also. But this will not help the proposal in question because delusions are supposed to be understood as playing the role of framework propositions not merely statements of what are normally framework propositions acting, unusually, as empirical judgements. So, for the proposal to work - for it to enable us to have some understanding of delusions as a whole by thinking of them as abnormal framework propositions - we need to be able to understand the idea of a genuinely different framework proposition. It is not clear that we can.

There seem to be two possible ways to try to understand this idea. One would be to conceive of an entirely different worldview including a distinct set of knowledge claims and background certainties which carved up the world in a different way to our own and which resisted translation into ours. Such an approach might fit the description, mentioned earlier, that schizophrenic delusions comprise a global 'existential' orientation to the world. It would, however, require successfully undermining familiar Davidsonian and McDowellian arguments against the very idea of factoring a worldview out into a neutral world and a linguistic structure [Davidson 1984: 183-98; McDowell 1994].

The other, initially more plausible, route is to postulate merely a local breakdown of the shared background of certainties in a small number of abnormal framework propositions. Given that the breakdown is merely local, the normal rational connections between it and the rest of the background of shared certainties will be ruptured. It is this breakdown that explains the strangeness of the corresponding delusion. But it also suggests that the abnormal propositions both have a kind of sense, because they are framework propositions, but of a nonsensical kind because they cannot be accommodated within a coherent worldview. It is by no means clear that we can hold onto this idea. Wittgenstein himself is dismissive of the idea of substantial notion of nonsense.

When a sentence is called senseless, it is not as it were its sense that is senseless. But a combination of words is being excluded from the language, withdrawn from circulation. [Wittgenstein 1953 §500]

Whilst that remark is made in the context of a discussion of grammatical rules, it applies also in this case because, although the proposal trades on the epistemic role of framework propositions, that role goes hand in hand with a sense giving role akin to that of grammatical rules. And that undermines the prospect of using abnormal framework propositions to understand the kind of content involved in delusions because no account has been given to justify the thought that they are playing that role. 
One might, of course, object that there is nothing problematic about the idea of using different grammatical rules. Some combinations of words in English have no current usage; they have no sense (not even a nonsensical sense). But they can be given one.

When I say that the orders "Bring me sugar" and "Bring me milk" make sense, but not the combination "Milk me sugar", that does not mean that the utterance of this combination of words has no effect. And if its effect is that the other person stares at me and gapes, I don't on that account call it the order to stare and gape, even if that was precisely the effect that I wanted to produce. [Wittgenstein 1953 §498]

'Milk me sugar' does not mean stand and gape. In English, as it stands, it has no meaning. But it could be given a meaning in a number of ways. The meanings of the individual words might be changed so that it meant, for example, bring me sugar. Or the phrase as a whole could be given an arbitrary meaning independently of its internal structure. But the possibility of such changes to English to generate a different but readily interpretable grammar does not help capture the strangeness of delusions. For that, one needs something more like the idea that a speaker is using abnormal grammar in this way: the words have their standard meaning; the compositional structure of their dialect of English is standard; they are using the phrase 'milk me sugar' not as a poetic incantation but to mean something; but it has no meaning for us. With these constraints in place, the mere idea of a locally abnormal grammar does not amount to a thinkable thought. Nor, in the context of the proposal, does an abnormal framework proposition.

\section{There are no 'external’ criteria for framework propositions.}

Despite the fact that framework propositions are usually identified piecemeal and from within a worldview and the fact that, because they play a sense determining role, understanding abnormal propositions is none too easy, there is another possibility suggested by the mechanical labels 'framework' and 'hinge' propositions. These labels suggest the possibility of a description of the structures of thought independent of its meaning or content.

If one could identity the bearers of content - by contrast with the content itself - within the mind in, perhaps, syntactic terms, it might seem possible to identify some thoughts which were held fast whilst other thoughts 'turned about' them. If the structure of thoughts could be described from such an external perspective then delusions could be identified with some such framework propositions, even though they were not themselves understandable. In other words, the proposal to equate delusions and framework propositions might presuppose a view of thought as though sideways on or from cosmic exile [McDowell 1994: 34; Quine 1975: 1960: 275].

This idea faces two very substantial difficulties. Firstly, it presupposes the possibility of the reduction of meaning to isomorphic structural entities in the head. Although this is a very influential idea and perhaps even the dominant form of naturalism in the philosophy of thought there are grave difficulties in capturing the normativity of thought in non-normative terms [Thornton 1998].

Secondly, the idea falls foul of Wittgenstein's suggestion that at least some framework propositions are not mental states at all.

If the shopkeeper wanted to investigate each of his apples without any reason, for the sake of being certain about everything, why doesn't he have to investigate his investigation? And can one talk of belief here (I mean belief as in 'religious belief', not surmise)? All psychological terms merely distract us from the thing that really matters. [Wittgenstein 1969 §318-9]

Indeed, there is some difficulty in characterising our attitudes to the 'propositions' which comprise the background described in On Certainty. As Wittgenstein stresses, they are typically not claims we make. Against Moore, he argues that we do not know that 'this is a hand' because it 
not the sort of thing we could doubt or provide grounds for. But neither are they beliefs or assumptions. This is one of the things wrong with Eilan's account of the proposal, for example. It seems implausible to say, for example, that we believe that 'There are lots of objects in the world', 'The world has existed for quite a long time', 'There are some chairs and tables in this room', 'This is one hand and this is another', and so on. Rather, they certainties expressed by our actions.

"We could doubt every single one of these facts, but we could not doubt them all." Wouldn't it be more correct to say: "we do not doubt them all".

Our not doubting them all is simply our manner of judging, and therefore of acting. [Wittgenstein 1969 §232]

Why do I not satisfy myself that I have two feet when I want to get up from a chair? There is no why. I simply don’t. This is how I act. [Wittgenstein 1969 §148]

Given the non-psychological and pre-epistemic account of framework propositions, the idea of theorising about them from a perspective outside meaning as encoded in inner representations which are describable in merely syntactic terms is a non-starter. Given that the idea of understanding from a shared inner perspective also fails, framework propositions do not look to help with any positive account of delusions.

\section{4: Conclusion}

Jaspers emphasises the role of understanding within psychopathology and thus psychiatry to balance the role of causal, nomological explanation. But he also argues that central aspects of psychopathology - primary delusions - cannot be understood. They are, on the one hand, mental rather than merely brutely causal phenomena. But, on the other, they cannot be grasped through the paradigmatic method of making sense of mental phenomena.

Recent models within the philosophy of psychiatry have attempted to display the logic of delusions in such a way that they can be at least partially understood: to 'solve simultaneously for understanding and utter strangeness'. In this paper I have considered the idea that delusions are abnormal framework propositions. But, as I have argued, although it suggests a number of interesting promising partial parallels it does not provide a route to understanding how delusions can seem the proper subject of understanding or empathy whilst remaining ultimately beyond its limits.

Perhaps, however, that is unsurprising. Perhaps the problem is that a condition of adequacy of an interpretative approach is that it should depict the utter strangeness of at least some central psychopathological phenomena and that is an impossible task. Interpreting or understanding but still finding utter strangeness are incompatible goals. If so then framework propositions are better deployed not as an aid to understanding the idea of delusions but rather as part of an explanation of why they are not understandable.

The idea is this. Wittgenstein sets out as 'from within' an articulation of the structure of a worldview which includes grammatical rules governing descriptions, a background of framework conditions and empirical claims made against that. (In fact, 'from within' is potentially misleading as it implies that an external view is also possible whilst it has been my contention here that no such external view is possible which keeps meaning in view. But I use the qualification to keep the focus on charting shared connections: sinking ourselves into the situation, in Jaspers' phrase.) A perspicuous representation of the structure reveals its interconnectedness. Thus a breakdown in, for example, the structure of framework propositions would threaten the rational intelligibility of the whole. Delusion can then plausibly be theorized about as resulting from - or being identical with - such a breakdown of the pre-epistemic background conditions for a worldview without making the further additional claim that a 
particular delusion is, partially understandably, a particular abnormal framework belief or proposition.

The difference between the Campbell-Eilan approach and this view is that between thinking that the structure of intelligibility has a local distortion - corresponding to the delusion as framework belief or proposition - and thinking that a precondition for a generally intelligible intentionality has been partially violated. (The related idea that delusions are failures in the preconditions of intentionality, best characterised from an engaged rather than an alienated epistemology, is set out in Gipps and Fulford 2004.)

The Italian psychiatrist and phenomenologist Giovanni Stanghellini comes close to this view. In his book Disembodied Spirits and Deanimated Bodies [Stanghellini 2004], he seems to tread a middle ground between an external characterisation and partial explanation of schizophrenia and a shared internal and empathic understanding. On the one hand, he suggests that schizophrenia can be seen as a breakdown of three distinct areas: the ability to synthesise different senses into a coherent perspective on the world (coenesthia); the ability to share a common worldview with other members of a community (sensus communis); and a basic pre-intellectual grasp of, or attunement to, social relations (attunement). Stanghellini says: 'The philosophical kernal of my proposal is to show how all these dimensions of the phenomenon of common sense (coenesthia, sensus communis, and attunement) are related to each other' [Stanghellini 2004: 10].

On the other hand, Stanghellini does not attempt to use these ideas to step wholeheartedly inside the worldview of subjects with schizophrenia. Rather, breakdowns of these are postulated as clues to interpret the strange things that sufferers report. But a basic phenomenon remains: the inaccessibility of experiences and thoughts.

Listening to a person affected by schizophrenia is a puzzling experience for more than one reason. If I let his words actualize in me the experiences he reports, instead of merely taking them as symptoms of an illness, the rock of certainties on which my life is based may be shaken in its most fundamental features. The sense of being $m e$ the one who is now seeing this sheet, reading these lines and turning this page; the experience of perceptual unity between my seeing this book, touching its cover and smelling the scent of freshly printed pages; the feeling that it is me the one who agrees or disagrees with what I am reading; the sense of belonging to a community of people, of being attuned to the others and involved in my actions and future; the taken-for-granted of all these doubtless features of everyday life, may be put at jeopardy.

Although my efforts to understand, by suspending all clinical judgement, allow me to see these person's self-reports as a possible configuration of human consciousness, I must admit that there is something incomprehensible and almost inhuman in these experiences, something that makes me feel radically different from the person I am listening to. [Stanghellini 2004: 111]

This may be as close as we can get to the idea of making sense of the idea of delusions through that of framework propositions. It is not that we can understand the idea of an abnormal framework proposition and thus understand delusions as abnormal framework propositions. But rather, inspecting the structure of our own worldview, we can see that a precondition of making knowledge claims is holding a background certain. And thus we can see that such a worldview is vulnerable to failures in that background. But this does not enable us to make sense of such failures. Failure here undermines the very possibility of shared sense and thus of apportioning precise meaning to delusions.

\section{Bibliography}

Berrios, G. (1991) 'Delusions as “wrong beliefs”: a conceptual history’ The British Journal of Psychiatry 159 supplement 14: 6-13 
Campbell, J. (2001) 'Rationality, meaning, and the analysis of delusion' in Philosophy Psychiatry and Psychology 8: 89-100

Davidson, D. (1984) Inquiries into Truth and Interpretation, Oxford: Oxford University Press

Eilan, N. (2000) 'On understanding schizophrenia' in Zahavi, D. (ed) Exploring the self, Amsterdam: John Benjamins: 97-113

Frith, C. (1992) The Cognitive Neuropsychology of Schizophrenia, Hove : Lawrence Erlbaum

Fulford, K.W.M. (1989) Moral Theory and Medical Practice, Cambridge: Cambridge University Press

Gipps, R.G.T., and Fulford, K.W.M. (2004) 'Understanding the clinical concept of delusion: From an estranged to an engaged epistemology' International Review of Psychiatry 16: 225-35

Glock, H.-J. (1996) A Wittgenstein Dictionary, Oxford: Blackwell

Heal, J. (1995) 'Replication and functionalism' in Davies, M. and Stone, T. (eds) Folk Psychology, Oxford: Blackwell: 45-59

Jaspers, K. ([1912] 1968) 'The phenomenological approach in psychopathology’ British Journal of Psychiatry 114: 1313-1323

Jaspers, K. ([1913] 1974) 'Causal and "Meaningful” Connections between Life History and Psychosis', trans. by J. Hoenig, in Hirsch, S.R., and Shepherd, M. (eds) Themes and Variations in European Psychiatry, Bristol: Wright: 80-93

Jaspers, K. ([1913] 1997) General psychopathology, Baltimore: Johns Hopkins University Press

Maher, B.A. (1999) 'Anomalous experience in everyday life: its significance for psychopathology' Monist 82: 547-570

McDowell, J. (1994) Mind and World, Cambridge, Mass.: Harvard University Press

Nagel, T. (1986) The View from Nowhere, Oxford Oxford University Press

Quine, W.V.O. (1960) Word and Object, Cambridge, M.A.: MIT Press

Sass, L.A. (1994) The Paradoxes of Delusion, New York: Cornell

Stanghellini, G. (2004) Disembodied Spirits and Deanimated Bodies, Oxford: Oxford University Press

Thornton, T. (1998) Wittgenstein on Language and Thought, Edinburgh: Edinburgh University Press

Wittgenstein, L. (1953) Philosophical Investigations, Oxford: Blackwell

Wittgenstein, L. (1967) Zettel, Oxford: Blackwell

Wittgenstein, L. (1969) On Certainty, Oxford: Blackwell

Wittgenstein, L. (1975) Philosophical Remarks, Oxford: Blackwell

September 3, 2007 